\title{
Analyzing the Effect of Machining Parameters Setting to the Surface Roughness during End Milling of CFRP-Aluminium Composite Laminates
}

\author{
M. Nurhaniza, ${ }^{1}$ M. K. A. M. Ariffin, ${ }^{1}$ F. Mustapha, ${ }^{2}$ and B. T. H. T. Baharudin ${ }^{1}$ \\ ${ }^{1}$ Department of Mechanical and Manufacturing Engineering, Universiti Putra Malaysia, 43400 Serdang, Selangor, Malaysia \\ ${ }^{2}$ Department of Aerospace Engineering, Universiti Putra Malaysia, 43400 Serdang, Selangor, Malaysia \\ Correspondence should be addressed to M. K. A. M. Ariffin; khairol@upm.edu.my
}

Received 19 September 2015; Revised 18 January 2016; Accepted 8 February 2016

Academic Editor: Thomas R. Kurfess

Copyright $\odot 2016$ M. Nurhaniza et al. This is an open access article distributed under the Creative Commons Attribution License, which permits unrestricted use, distribution, and reproduction in any medium, provided the original work is properly cited.

\begin{abstract}
The quality of the machining is measured from surface finished and it is considered as the most important aspect in composite machining. An appropriate and optimum machining parameters setting is crucial during machining operation in order to enhance the surface quality. The objective of this research is to analyze the effect of machining parameters on the surface quality of CFRPAluminium in CNC end milling operation with PCD tool. The milling parameters evaluated are spindle speed, feed rate, and depth of cut. The $\mathrm{L}_{9}$ Taguchi orthogonal arrays, signal-to-noise $(S / N)$ ratio, and analysis of variance (ANOVA) are employed to analyze the effect of these cutting parameters. The analysis of the results indicates that the optimal cutting parameters combination for good surface finish is high cutting speed, low feed rate, and low depth of cut.
\end{abstract}

\section{Introduction}

Machining parameters and process of composite materials are important to produce the necessary part for resulting assembly and achieved required geometrical shapes and dimensional tolerances. Conventional machining process such as milling, drilling, turning, abrasive cutting, and grinding are frequently used for producing complex characteristic of composite part. Normally it is done by removing materials in term of chips formation. The shape and size of chip removed, material removal rate, and excellent surface finish are directly related to the kinematic relationship between the cutting tool and workpiece [1].

Commonly, composite product is produced with nearnet shapes and requires a secondary process. The manufacturer will use milling process for removing the unnecessary material to the required geometrical shape, dimensional tolerances, and high quality finished. As mentioned in [2], milling operation is used as a corrective machining process in composite manufacturing so that good and high quality surfaces are achieved. The type of fiber used in composites has greater influence in selection of cutting tools and machining parameters. It is important to ensure that the tool selected for machining process is suitable for material. The knowledge of cutting mechanism is essential to optimize the machinability in milling. Surface roughness has a main influence on dimensional precision, performance of mechanical pieces, and production costs [3]. For these reasons, the manufacturer are carried out for optimizing the cutting condition to reach the specific surface roughness [4-6]. The demand for high quality and fully automated production focuses on the surface condition of product manufactured especially the roughness of the machined surface due to the effect on product appearance, function, and reliability and importance to be consistent in the tolerance and surface finish [7]. Surface roughness also influences diagnosing of the stability of machining process where reducing the surface quality may indicate the workpiece material nonhomogeneity, progressive tool wear, cutting tool chatter, and so forth [8].

Previous works from various researchers reported that the surface roughness and delamination factor are strongly dependent on cutting parameters, tool geometry, and resultant machining force [9-11]. In every machining process, cutting speed had strong influence on the quality of surface 
finish. Most of the researchers found that increasing of cutting speed improves the surface finish where the surface roughness is decreased and at the same time machinability is improved [4, 9-12]. Gökkaya [12] found that the best cutting speed to obtain the minimum roughness average $\left(R_{a}\right)$ is in the range of $200 \mathrm{~m} / \mathrm{min}$ for all feed rates. Santhanakrishnan et al. [9] found that the minimum value of $R_{a}$ is on the highest speed which is $500 \mathrm{~m} / \mathrm{min}$ and $0.10 \mathrm{~mm} / \mathrm{rev}$ of feed rate. However, feed rate is more dominant in determining the surface roughness of machined product. The increasing of feed rate leads to the increasing of surface roughness which decreases the quality of surface finish $[4,5,9,13-16]$. In end milling, the use of high cutting speed and low feed rate $(0.01 \mathrm{~mm}$ per tooth) is recommended to obtain better surface finish for a specific test range [14]. Al Hazza and Adesta [15] defined that the lowest feed rate $\left(0.05 \mathrm{~mm} \mathrm{rev}^{-1}\right)$ and highest cutting speed caused the optimal surface roughness value.

In order to get good surface quality, it is necessary to use optimization technique to find optimal machining parameters. This paper investigates the effect of machining parameters on the quality of surface finish of CFRP-Aluminium composite laminate using Taguchi design of experiment (DOE) method. Taguchi method is able to systematically formulate the experimental layout, analyze the considerable influence of each experimental parameter using statistical analysis of variance (ANOVA), and after all determine the optimal parameters combination to yield the best machining condition. Taguchi used the signal-to-noise $(S / N)$ ratio as the quality characteristic of choice. $S / N$ ratio can represent the average (mean) and variation (standard deviation) of the experimental results $[9,10]$. The machining parameters involved in this experiment are cutting speed, feed rate, and depth of cut. The main objective is to find the combination of machining parameters to achieve low surface roughness during end milling.

\section{Material and Method}

In the present work, a series of machining tests are carried out using HAAS CNC Milling VF-6 machine to do the machining operation of CFRP-Aluminium composite laminate. The machining processes are performed under dry conditions. Meanwhile, the workpiece materials having the size $100 \mathrm{~mm}$ $\times 100 \mathrm{~mm} \times 7 \pm 0.5 \mathrm{~mm}$ is made by the combination of carbon fiber reinforced polymer (CFRP) and aluminium alloy 2024-T3. In this experiment, the selected cutting tool is polycrystalline diamond (PCD) end mill with $6 \mathrm{~mm}$ diameter and $0.2 \mathrm{~mm}$ corner radius.

2.1. Workpiece Fabrication. The workpiece for the end milling experiments is fabricated using two layers of aluminium alloy 2024-T3 and 18 layers of unidirectional carbon fiber (UDCF) prepregs as the epoxy resins are the matrix material. The CFRP-Aluminium composite laminates are fabricated using autoclave process with the following parameters: pressure 85 $+15 /-0 \mathrm{psi}$, vacuum $22 \mathrm{Hg}$, temperature $355^{\circ} \mathrm{F}$, curing time $120-135 \mathrm{~min}$, and heating and cooling rate $0.3-4.0^{\circ} \mathrm{C} / \mathrm{min}$. This process provides higher volume fraction and reduced voids in terms of the final quality of the laminates produced

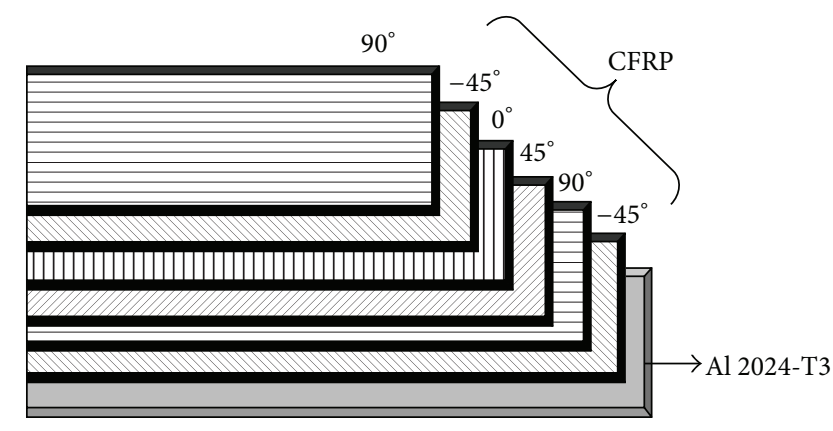

FIGURE 1: Scheme of CFRP-Aluminium laminate.

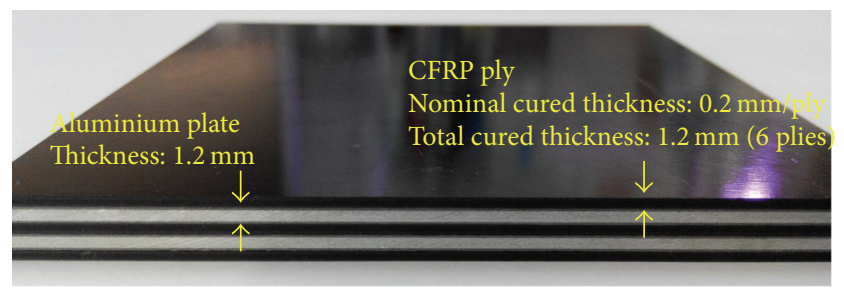

FIGURE 2: Final workpiece for experiment.

as well as having a safer and cleaner fabrication environment. During the fabrication, the UDCF prepregs are laminated in $0^{\circ}, 45^{\circ}$, and $90^{\circ}$ directions and layered with $\mathrm{Al} \mathrm{2024- \textrm {T } 3}$ alternately. Figure 1 shows the layup arrangement of CFRPAluminium composite laminates. After curing process, the composite laminates are cut and trimmed into required size: $100 \mathrm{~mm} \times 100 \mathrm{~mm} \times 7 \mathrm{~mm}$. Figure 2 shows the workpiece for this experiments.

2.2. Milling Process. As previously mentioned, the machining operations are carried out using HAAS CNC Milling VF-6 machine as shown in Figure 3(a) under dry condition. An end mill used in this experiment is double tooth cutter with cutting edges of PCD; see Figure 3(b). The numerical control (NC) codes are generated using MASTERCAM software. The codes contain the machining parameters such as cutting speed, feed rate, and depth of cut and the info needed like machining period, type of workpiece material, and type of cutting tool. Figure 4 shows the tool engagement on workpiece. The sections that need to be machined and the workpiece after being machined are shown in Figures 5(a)5(b). Each section gives different effect on machining process.

(i) Section 1 (S1) represents the effect of machining on pocket.

(ii) Section 2 (S2) represents the effect of machining on corner part.

(iii) Section 3 (S3) represents the effect of machining on simple part.

2.3. Surface Roughness Measurement. The centre line average $\left(R_{a}\right)$ is commonly used for surface roughness measurement using MarSurf PS1 as shown in Figure 6. This device is a compact roughness measuring instrument for mobile use. 


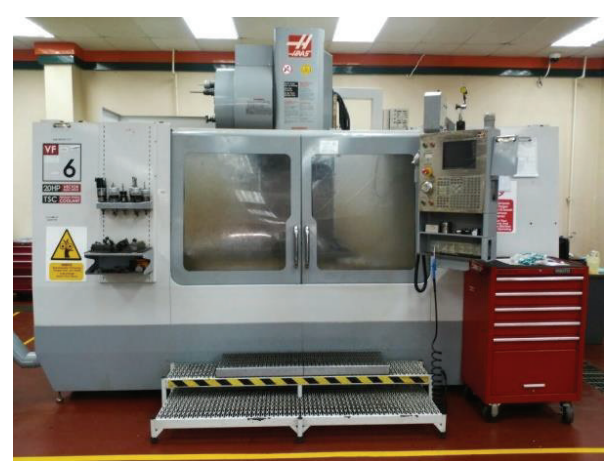

(a)
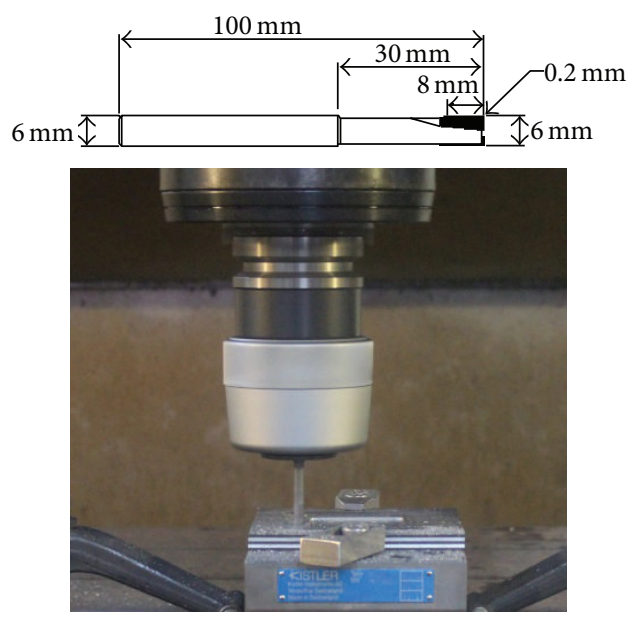

(b)

FIgURE 3: (a) HAAS CNC milling machine; (b) PCD end mill with double tooth cutter.

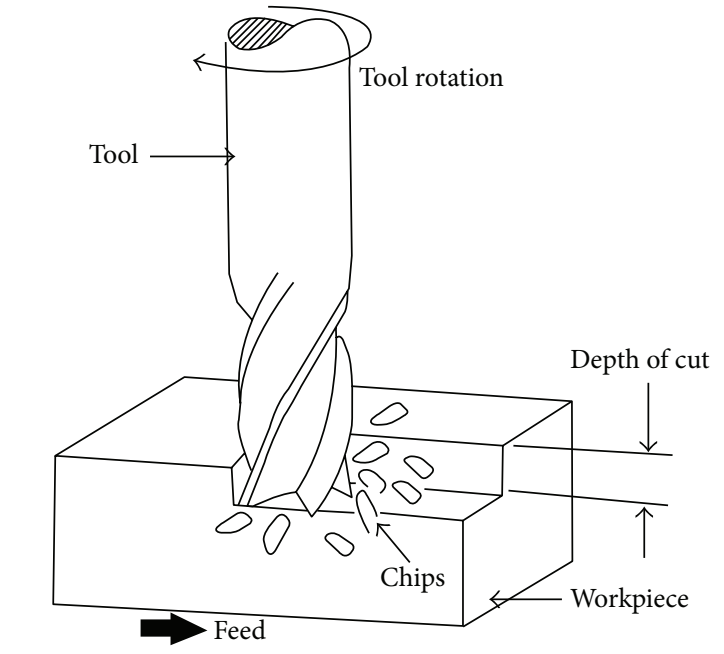

(Workpiece is moved and tool is stationary)

FIgURE 4: Tool engagement on workpiece material.

The maximum measuring range of MarSurf PS1 is $350 \mu \mathrm{m}$ (0.014 in) $(-20 \mu \mathrm{m}$ to $+150 \mu \mathrm{m})(-0.008$ in to +0.006 in). The measurements are made along the feed direction of the milled surface and the $R_{a}$ values are the average of five measurements for each section.

\section{Experimental Design}

The experiment is performed to investigate the effect of one or more factors of process parameters on quality of surface finish. In this study, Taguchi design of experiment (DOE) is used to design the experimental matrix. Taguchi method is a systematic method to plan the experiment based specially on design of orthogonal array (OA) that can significantly reduce the number of experiments but in highly acceptable results.

The three important machining parameters involved in this experiment are cutting speed, feed rate, and depth of cut, which affected the surface roughness $R_{a}$ of machined surface. Three different levels, 1 (low), 2 (medium), and 3 (high), of each parameter are selected for experimentation which represent the typical range of machining parameters employed in industry using PCD cutter. The range of machining conditions is selected based on the range suggested by the cutting tool manufacturer, VHF Camfacture AG. By considering the workpiece consisting of two different materials, the range of each parameter has to be in the range of aluminium and carbon reinforced plastic (CRP). The selected experimental parameters and their levels are indicated in Table 1.

In traditional full factorial, there are 27 experiments needed to complete all the experimental works of three factors and three levels. However, by using Taguchi method, with selected parameters and levels, current parametric study could be well performed using $\mathrm{L}_{9} \mathrm{OA}$ where only nine experiments should be run to complete the array.

\section{Results and Analysis}

The objective of this experiment is to optimize the milling parameters to get minimum surface roughness of machined surface using the smaller the better characteristics. Table 2 shows the actual data for surface roughness of three different sections (S1, S2, and S3) with their calculated $S / N$ ratio, whereas Tables 3(a)-3(c) show the mean $S / N$ ratio for each level for S1, S2, and S3, respectively. Their data are then plotted as shown in Figures 7(a)-7(c), respectively.

The quality characteristic for surface roughness is the smaller the better. The $S / N$ ratio of each experimental run is calculated using the following equation:

$$
S / N=-10 \log \left(\frac{1}{n} \sum_{i=1}^{n} x^{2}\right),
$$

where $n$ is the number of observations and $x$ is the observed data.

The surface roughness data are analyzed using Taguchi method. Taguchi suggested analyzing the means and $S / N$ 


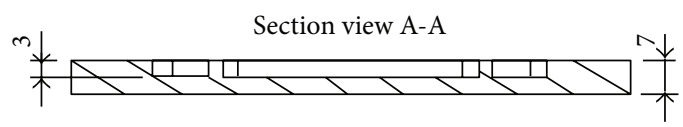

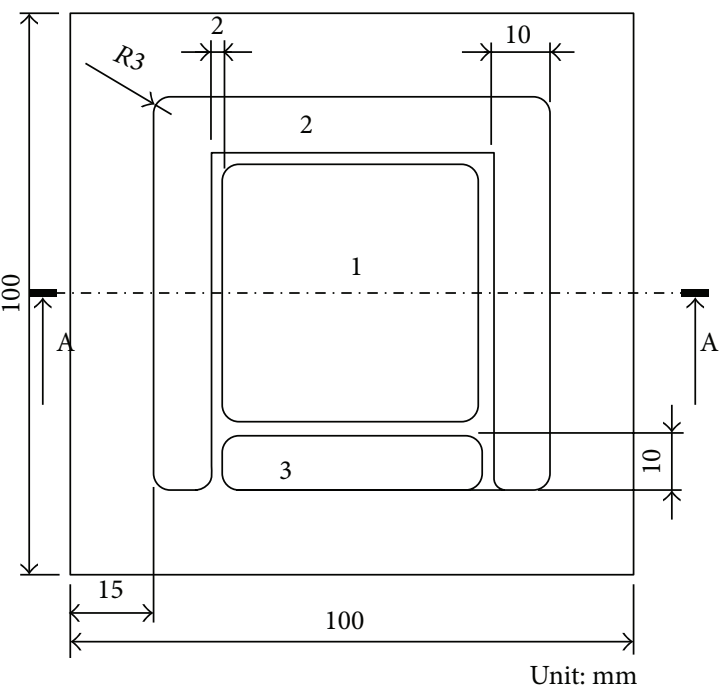

(a)

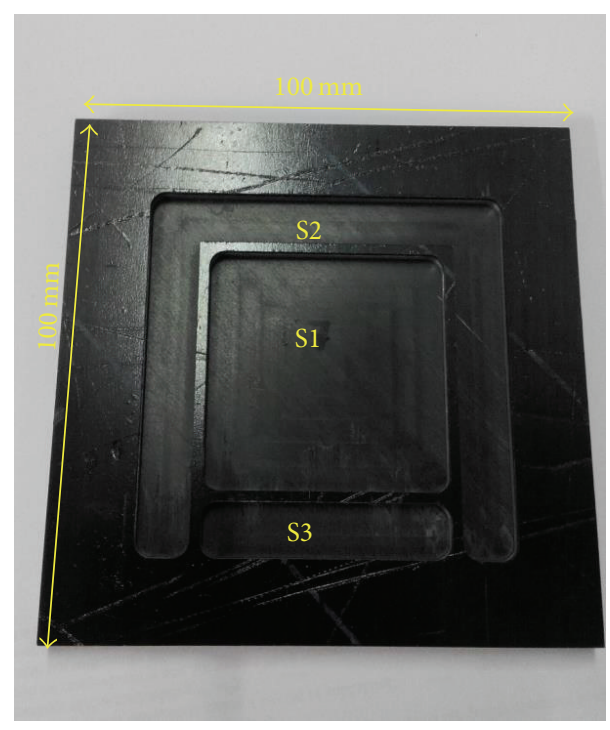

(b)

Figure 5: (a) The sections that need to be machined; (b) workpiece after being machined.

TABLE 1: Machining parameters and levels.

\begin{tabular}{lccr}
\hline Factor & \multicolumn{2}{c}{ Level } & \multicolumn{1}{c}{3} \\
\hline A: spindle speed (RPM) & 1 & 4000 & 5000 \\
B: feed rate (mm/min) & 3000 & 1200 & 1600 \\
C: depth of cut $(\mathrm{mm})$ & 800 & 0.3 & 0.375 \\
\hline
\end{tabular}

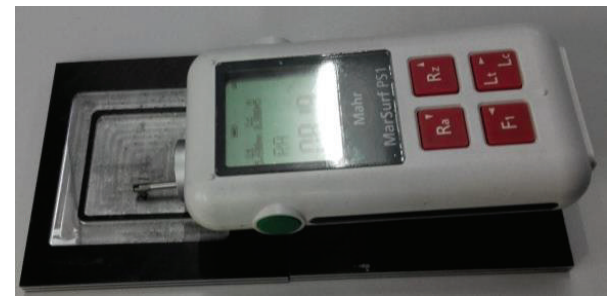

FIGURE 6: Surface roughness measuring procedure.

ratio using conceptual approach that concerned graphing the effect and visually identifying the factors that come out to be significant without using ANOVA to make the simplest analysis. Analysis of the effect of machining parameters is carried out on $S / N$ ratios of machinability output using response table and analysis of variance (ANOVA). Response table allowed the direct identification of parameters effect to the surface roughness by viewing the difference between the maximum and minimum $S / N$ ratio values. The higher the difference is, the stronger the influence the factor will have on surface roughness.
The three sections show the same pattern of optimum machining parameters even though the $R_{a}$ values are different in each section. Combination of feed rate and cutting speed provides the strongest effect on $R_{a}$ where feed rate is the dominant factor at $62.67 \%$ for S1, $49.49 \%$ for S2, and $52.34 \%$ for S3, and cutting speed is the dominant factor at $17.24 \%$ for S1, 22.28\% for S2, and $25.72 \%$ for S3 as shown in ANOVA in Tables 4(a)-4(c).

For further understanding the effect of main parameters, the surface plots of surface roughness against the parameters are created in Figures 8(a)-8(c). The figures show the interaction of feed rate and spindle speed to the surface roughness. It is found that the higher spindle speed may decrease the surface roughness. The highest values of $R_{a}$ are found when the feed rate $=1600 \mathrm{~mm} / \mathrm{min}$ and spindle speed $=$ $3000 \mathrm{rpm}$. Generally, the combination of high spindle speed and low feed rate produces better surface finish, supported by previous findings of others. In the scanning electron microscope (SEM) images as shown in Figure 9, it is apparent that sharp and brittle fractures of fiber indicate the failure modes. From the figure, it is found that the highest speed and lowest feed rate give the better surface finish. 

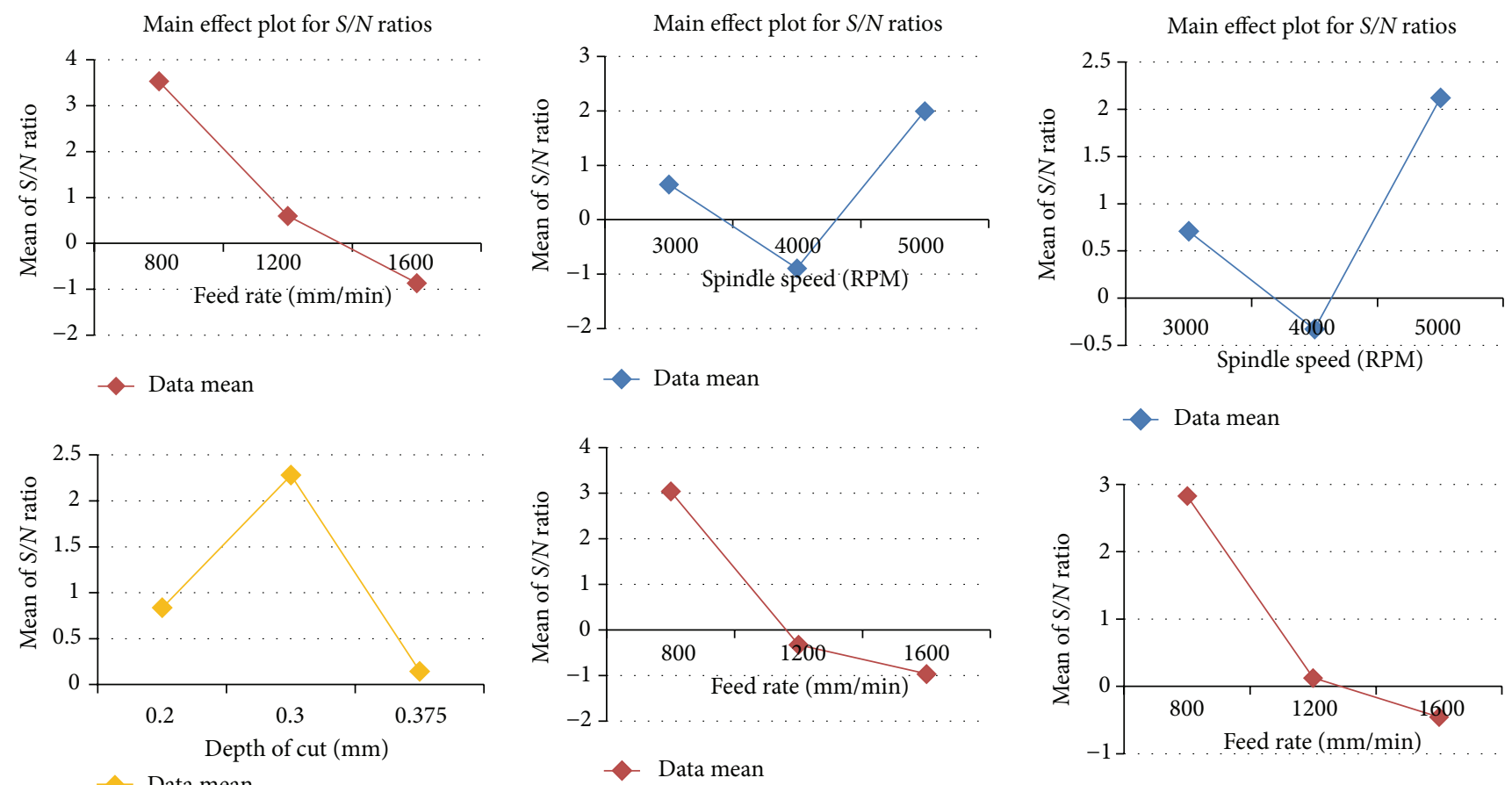

Data mean
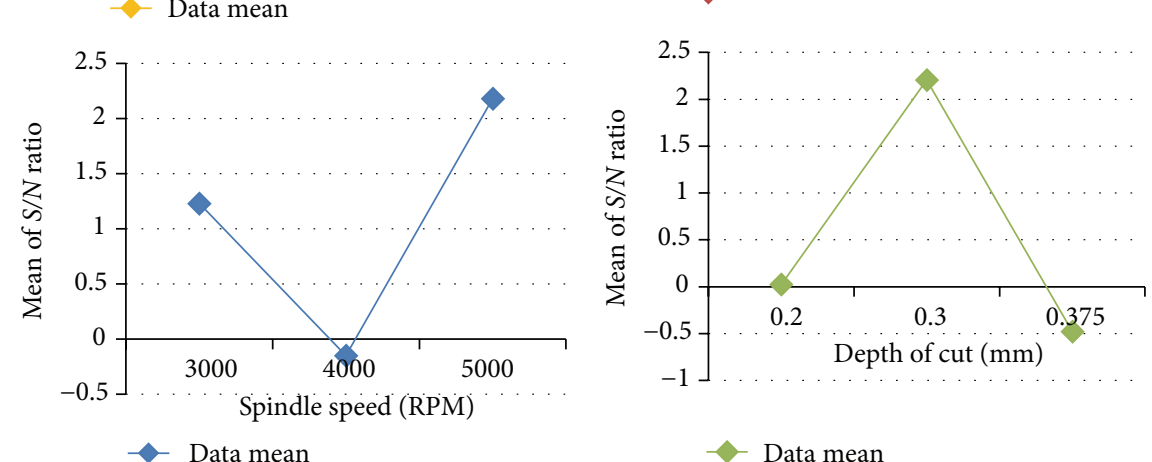

(b) S2
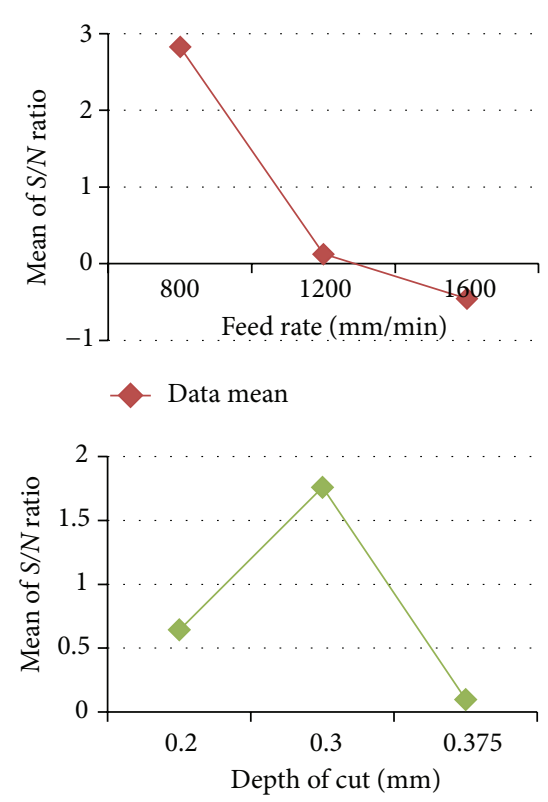

(a) $\mathrm{S} 1$

FIGURE 7: Signal-to-noise ratio graph of surface roughness.

TABLE 2: Experimental result and the calculated $S / N$ ratio.

\begin{tabular}{|c|c|c|c|c|c|c|c|c|c|}
\hline \multirow{2}{*}{ Number of experiments } & \multicolumn{3}{|c|}{ Factor } & \multicolumn{3}{|c|}{ Surface roughness $\left(R_{a}\right)$} & \multicolumn{3}{|c|}{ Calculated $S / N$ ratio } \\
\hline & $\mathrm{A}$ & $\mathrm{B}$ & $\mathrm{C}$ & S1 & S2 & S3 & $S / N$ S1 & S/N S2 & S/N S3 \\
\hline 1 & 1 & 1 & 1 & 0.6612 & 0.7418 & 0.7754 & 3.59334 & 2.59426 & 2.20948 \\
\hline 2 & 1 & 2 & 2 & 0.869 & 0.9374 & 0.958 & 1.21960 & 0.56150 & 0.37269 \\
\hline 3 & 1 & 3 & 3 & 1.138 & 1.1494 & 1.054 & -1.12285 & -1.20942 & -0.45681 \\
\hline 4 & 2 & 1 & 3 & 0.9296 & 1.0348 & 0.9576 & 0.63408 & -0.29713 & 0.37632 \\
\hline 5 & 2 & 2 & 1 & 1.0414 & 1.2034 & 1.0432 & -0.35235 & -1.60820 & -0.36735 \\
\hline 6 & 2 & 3 & 2 & 1.088 & 1.0924 & 1.1206 & -0.73258 & -0.76763 & -0.98901 \\
\hline 7 & 3 & 1 & 2 & 0.4812 & 0.456 & 0.5072 & 6.35349 & 6.82070 & 5.89642 \\
\hline 8 & 3 & 2 & 3 & 0.8992 & 0.992 & 0.9578 & 0.92287 & 0.06977 & 0.37450 \\
\hline 9 & 3 & 3 & 1 & 1.088 & 1.1108 & 0.9902 & -0.73258 & -0.91272 & 0.08554 \\
\hline
\end{tabular}




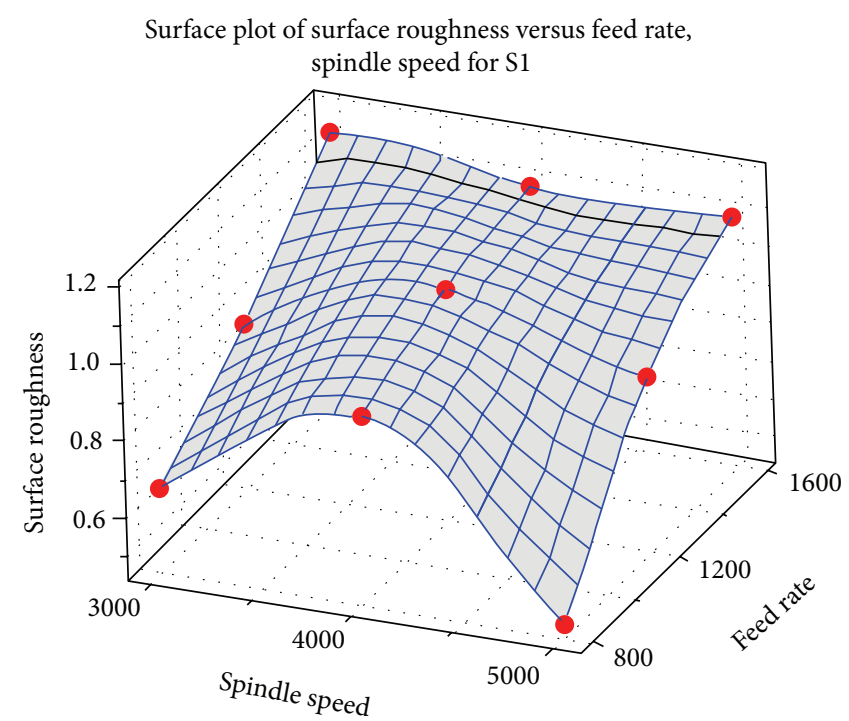

(a)

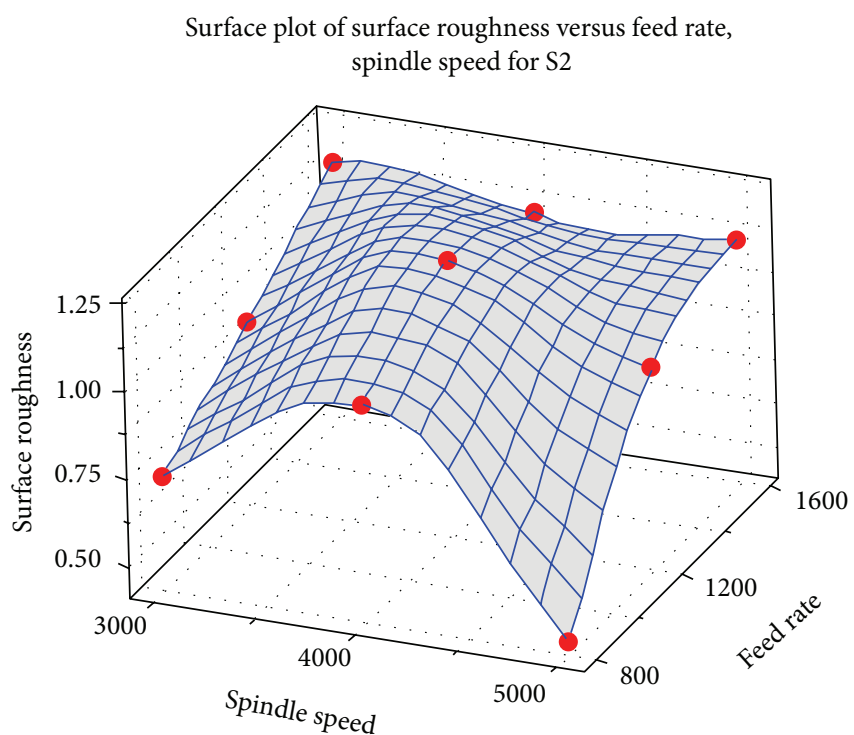

(b)

Surface plot of surface roughness versus feed rate, spindle speed for S3

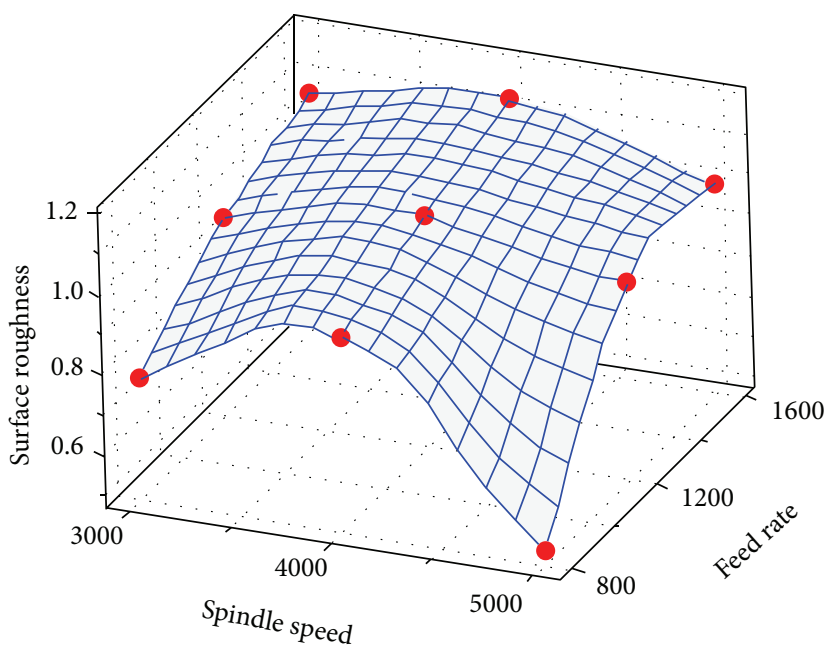

(c)

FIGURE 8: Effect of feed rate on surface roughness at different spindle speed.

\section{Discussions}

Surface roughness plays an important role in many areas and one of the factors of great importance in evaluation of machining accuracy. Machining parameters such as cutting speed, feed rate, and depth of cut have significant influence on the surface roughness for a given machining setup. The mechanism of machining process in CFRP-Aluminium composite is due to the combination of tool geometry, bending rupture shear, and plastic deformation and the mechanisms are dependent on the fiber orientation, the toughness of fiber and aluminium, and the flexibility of metal and fiber. These mechanisms form a surface texture on the workpiece [17].

The variation of surface roughness with respect to the machining parameters indicates that the surface roughness fluctuated for various spindle speed, feed rate, and depth of cut. The surface roughness is better at high spindle speed, low feed rate, and low depth of cut. With reference to Figure 9 the micrographs of workpiece surfaces after machining operation with different parameters. The micrographs show the surface profile obtained from low, medium, and high spindle speed and feed rate. The surface roughness is rapidly increased at the highest feed rate. The increase of feed rate leads to the increase of heat generated and thus tool wear which resulted in the higher surface roughness. The highest feed rate also results in increased chatter and produced incomplete machining at faster traverse and causes a higher surface roughness $[5,18]$.

The surface roughness data are analyzed using conceptual signal-to-noise $(S / N)$ ratio approach. The use of $S / N$ ratio for selecting the combination levels for surface roughness value 


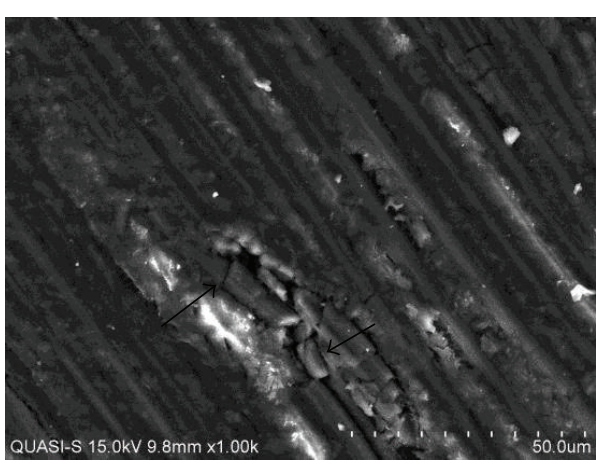

(a) Speed $=3000 \mathrm{RPM}$; feed rate $=1200 \mathrm{~mm} / \mathrm{min}$; depth of cut $=0.3 \mathrm{~mm}$

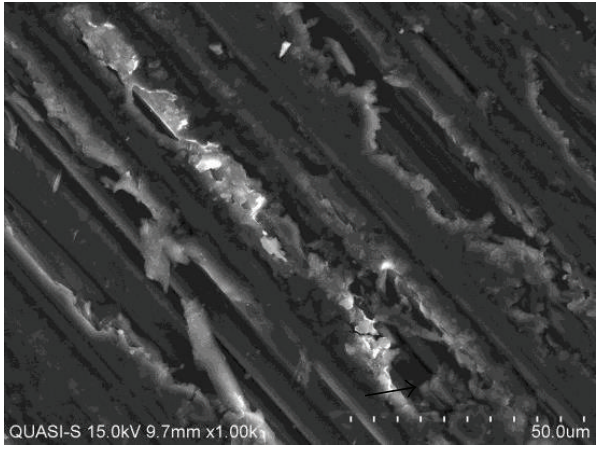

(b) Speed $=4000 \mathrm{RPM}$; feed rate $=1600 \mathrm{~mm} / \mathrm{min}$; depth of cut $=0.3 \mathrm{~mm}$

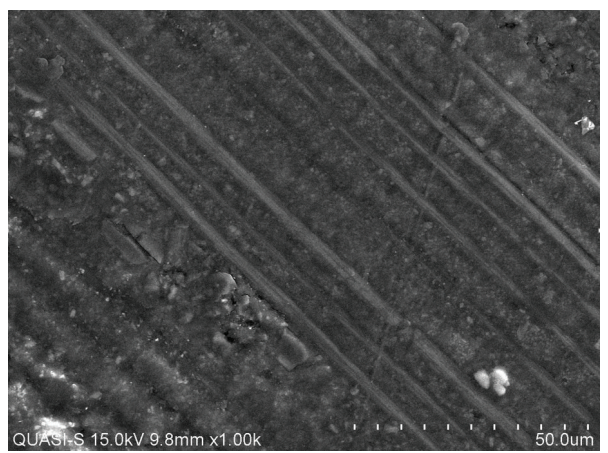

(c) Speed $=5000 \mathrm{RPM}$; feed rate $=800 \mathrm{~mm} / \mathrm{min}$; depth of cut $=0.3 \mathrm{~mm}$

FIGURE 9: Scanning electron micrographs of the machined surface.

TABLE 3: (a) Response table for average $S / N$ ratio for S1. (b) Response table for average $S / N$ ratio for S2. (c) Response table for average $S / N$ ratio for S3.

(a)

\begin{tabular}{|c|c|c|c|c|c|}
\hline \multirow{2}{*}{ Factor } & \multicolumn{3}{|c|}{ Level $(S / N)$} & \multirow{2}{*}{ Max-Min } & \multirow{2}{*}{ Rank } \\
\hline & 1 & 2 & 3 & & \\
\hline A & 1.23003 & -0.15028 & 2.18126 & 2.33155 & 2 \\
\hline B & 3.52697 & 0.59671 & -0.86267 & 4.38964 & 1 \\
\hline $\mathrm{C}$ & 0.83614 & 2.28017 & 0.14470 & 2.13547 & 3 \\
\hline
\end{tabular}

(b)

\begin{tabular}{|c|c|c|c|c|c|}
\hline \multirow{2}{*}{ Factor } & \multicolumn{3}{|c|}{ Level $(S / N)$} & \multirow{2}{*}{ Max-Min } & \multirow{2}{*}{ Rank } \\
\hline & 1 & 2 & 3 & & \\
\hline$\overline{\mathrm{A}}$ & 0.64878 & -0.89099 & 1.99258 & 2.88357 & 2 \\
\hline B & 3.03928 & -0.32564 & -0.96326 & 4.00254 & 1 \\
\hline $\mathrm{C}$ & 0.02445 & 2.20486 & -0.47893 & 2.68379 & 3 \\
\hline
\end{tabular}

(c)

\begin{tabular}{lccccc}
\hline Factor & & Level $(S / N)$ & Max-Min & Rank \\
& 1 & 2 & 3 & 2.11882 & 2.44550 \\
A & 0.70845 & -0.32668 & -0.45343 & 3.28083 & 1 \\
B & 2.82741 & 0.12661 & 0.09800 & 1.09599 & 3 \\
C & 0.64256 & 1.76003 & & \\
\hline
\end{tabular}


TABLE 4: (a) ANOVA result for S1. (b) ANOVA result for S2. (c) ANOVA result for S3.

(a)

\begin{tabular}{lccccc}
\hline Response factor & Sum of square & Degree of freedom & Mean square/variance & Ratio $(F)$ & \% contribution \\
\hline A & 8.24621 & 2 & 4.12311 & 3.31265 & 17.23556 \\
B & 29.98511 & 2 & 14.99256 & 12.04554 & 62.67243 \\
C & 7.12354 & 2 & 3.56177 & 2.86165 & 14.88905 \\
Error & 2.48931 & 2 & 1.24466 & 1 & 5.20296 \\
Total & 47.84418 & 8 & & 100 \\
\hline
\end{tabular}

(b)

\begin{tabular}{lccccc}
\hline Response factor & Sum of square & Degree of freedom & Mean square/variance & Ratio $(F)$ & \% contribution \\
\hline A & 12.49168 & 2 & 6.24584 & 3.45397 & 22.27946 \\
B & 27.74957 & 2 & 13.87479 & 7.67280 & 49.49258 \\
C & 12.21027 & 2 & 6.10514 & 3.37616 & 21.77756 \\
Error & 3.61662 & 2 & 1.80831 & 1 & 6.45040 \\
Total & 56.06814 & 8 & & 100 \\
\hline
\end{tabular}

(c)

\begin{tabular}{lccccc}
\hline Response factor & Sum of square & Degree of freedom & Mean square/variance & Ratio $(F)$ & \% contribution \\
\hline A & 9.04112 & 2 & 4.52056 & 2.65674 & 25.72415 \\
B & 18.39459 & 2 & 9.19729 & 5.40526 & 52.33702 \\
C & 4.30762 & 2 & 2.15381 & 1.26580 & 12.25622 \\
Error & 3.40309 & 2 & 1.70155 & 1 & 9.68261 \\
Total & 35.14642 & 8 & & 100 \\
\hline
\end{tabular}

recommends the use of low value of feed rate in order to get good surface finish. Feed rate is found to be the most significant effect to produce the minimum value of arithmetic average surface roughness $\left(R_{a}\right)$. The presented statistical analysis of factorial effect recommended that the combination of feed rate and cutting speed has significant effect on $R_{a}$. The $R_{a}$ values apparently increased with the increase of feed rate as shown in Figure 8, whereas the marginal improvement of $R_{a}$ regarding the increasing of cutting speed. As mentioned before, feed rate has more dominant influence on $R_{a}$ than cutting speed and depth of cut due to the influence of mechanism of chip formation [11]. The velocity of chip is faster at high cutting speed and low feed rate that lead a shorter time for the chip to be in contact with the new machined surface and the probability of the chip to left over the new formed surface is small [14]. The S3 has higher $R_{a}$ value compared to $R_{a}$ of $\mathrm{S} 1$ and S2. The stiffness of workpiece is reduced during machining S3 part due to the change of workpiece thickness, causing the increasing of $R_{a}$ and percentage error. S1 gives the best result of surface roughness due to the theory provided by Ghani et al. [19] that the cutting process should proceed from the least supported area to the best supported area which improves the stability of workpiece stiffness.

\section{Conclusion}

This study has presented the experimental investigation of end milling CFRP-Aluminium composite laminate using Taguchi design of experiment method. The following conclusions can be drawn based on the results obtained: (i) Feed rate has the most dominant factor in influencing the surface roughness, $R_{a}$, followed by spindle speed with each factor contributing as follow: $\mathrm{S} 1=62.67 \%$, $\mathrm{S} 2=49.49 \%, \mathrm{~S} 3=52.34 \%$ and $\mathrm{S} 1=17.24 \%, \mathrm{~S} 2=$ $22.28 \%, \mathrm{~S} 3=25.72 \%$, respectively.

(ii) The dominant effect of feed rate on surface roughness is possibly accredited to the different mechanism of chip formation at different feed rate.

(iii) SEM images are used to verify the surface integrity and morphology of the machined laminates.

(iv) The influence of depth of cut on surface roughness is insignificant.

(v) The parameters considered in the experiments are optimized to achieve minimum surface roughness using response table, normal probability plot, and analysis of variance (ANOVA) technique.

\section{Conflict of Interests}

The authors declare that there is no conflict of interests regarding the publication of this paper.

\section{Acknowledgments}

The authors acknowledge the financial support from Ministry of Science Technology and Innovation Malaysia (MOSTI) through eSciencefund grant (06-01-04-SF1896) and Ministry of Education Malaysia (MOE) for the MyPhD scholarship. 


\section{References}

[1] J. Y. Sheikh-Ahmad, Machining of Polymer Composites, Springer, New York, NY, USA, 2009.

[2] S. Jahanmir, M. Ramulu, and P. Koshy, Machining of Ceramics and Composites, Marcel Dekker, New York, NY, USA, 2000.

[3] M. Ramulu, C. W. Wern, and J. L. Garbini, "Effect of fibre direction on surface roughness measurements of machined graphite/ epoxy composite," Composites Manufacturing, vol. 4, no. 1, pp. 39-51, 1993.

[4] M. T. Hayajneh, M. S. Tahat, and J. Bluhm, "A study of the effects of machining parameters on the surface roughness in the endmilling process," Jordan Journal of Mechanical and Industrial Engineering, vol. 1, no. 1, pp. 1-5, 2007.

[5] J. Z. Zhang, J. C. Chen, and E. D. Kirby, "Surface roughness optimization in an end-milling operation using the Taguchi design method," Journal of Materials Processing Technology, vol. 184, no. 1-3, pp. 233-239, 2007.

[6] A. A. Sequeira, R. Prabhu, N. S. Sriram, and T. Bhat, "Effect of cutting parameters on cutting force and surface roughness of aluminium components using face milling process-a Taguchi approach," IOSR Journal of Mechanical and Civil Engineering, vol. 3, no. 4, pp. 7-13, 2012.

[7] N. S. K. Reddy and P. V. Rao, "Selection of optimum tool geometry and cutting conditions using a surface roughness prediction model for end milling," International Journal of Advanced Manufacturing Technology, vol. 26, no. 11-12, pp. 1202-1210, 2005.

[8] A. Hamdan, A. A. D. Sarhan, and M. Hamdi, "An optimization method of the machining parameters in high-speed machining of stainless steel using coated carbide tool for best surface finish," International Journal of Advanced Manufacturing Technology, vol. 58, no. 1-4, pp. 81-91, 2012.

[9] G. Santhanakrishnan, R. Krishnamurthy, and S. K. Malhotra, "Machinability characteristics of fiber reinforced plastics composites," Journal of Mechanical Working Technology, vol. 17, pp. 195-204, 1988.

[10] A. Koplev, A. Lystrup, and T. Vorm, "The cutting process, chips, and cutting forces in machining CFRP," Composites, vol. 14, no. 4, pp. 371-376, 1983.

[11] G. C. Everstine and T. G. Rogers, "A theory of machining of fiber-reinforced materials," Journal of Composite Materials, vol. 5, no. 1, pp. 94-106, 1971.

[12] H. Gökkaya, "The effects of machining parameters on cutting forces, surface roughness, built-up edge (BUE) and built-up layer (BUL) during machining AA2014 (T4) alloy," Journal of Mechanical Engineering, vol. 56, no. 9, pp. 584-593, 2010.

[13] B. A. Khidhir and B. Mohamed, "Study of cutting speed on surface roughness and chip formation when machining nickelbased alloy," Journal of Mechanical Science and Technology, vol. 24, no. 5, pp. 1053-1059, 2010.

[14] A. I. Azmi, R. J. T. Lin, and D. Bhattacharyya, "Machinability study of glass fibre-reinforced polymer composites during end milling," International Journal of Advanced Manufacturing Technology, vol. 64, no. 1-4, pp. 247-261, 2013.

[15] M. H. F. Al Hazza and E. Y. T. Adesta, "Investigation of the effect of cutting speed on the surface roughness parameters in CNC end milling using artificial neural network," IOP Conference Series Materials Science and Engineering, vol. 53, no. 1, Article ID 012089, 2013.

[16] D. K. Baek, T. J. Ko, and H. S. Kim, "Optimization of feedrate in a face milling operation using a surface roughness model,"
International Journal of Machine Tools and Manufacture, vol. 41, no. 3, pp. 451-462, 2001.

[17] K. Palanikumar, L. Karunamoorthy, and R. Karthikeyan, "Assessment of factors influencing surface roughness on the machining of glass fiber-reinforced polymer composites," Materials and Design, vol. 27, no. 10, pp. 862-871, 2006.

[18] N. S. Kumar, A. Shetty, A. Shetty, K. Ananth, and H. Shetty, "Effect of spindle speed and feed rate on surface roughness of carbon steels in CNC turning," Procedia Engineering, vol. 38, pp. 691-697, 2012, Proceedings of the International Conference on Modelling, Optimisation and Computing (ICMOC '12).

[19] J. A. Ghani, I. A. Choudhury, and H. H. Hassan, "Application of Taguchi method in the optimization of end milling parameters," Journal of Materials Processing Technology, vol. 145, no. 1, pp. 8492, 2004. 


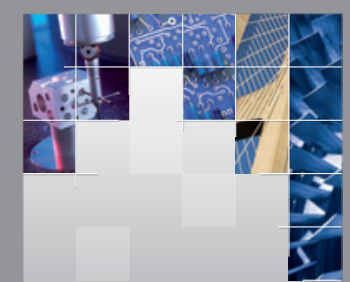

\section{Enfincering}
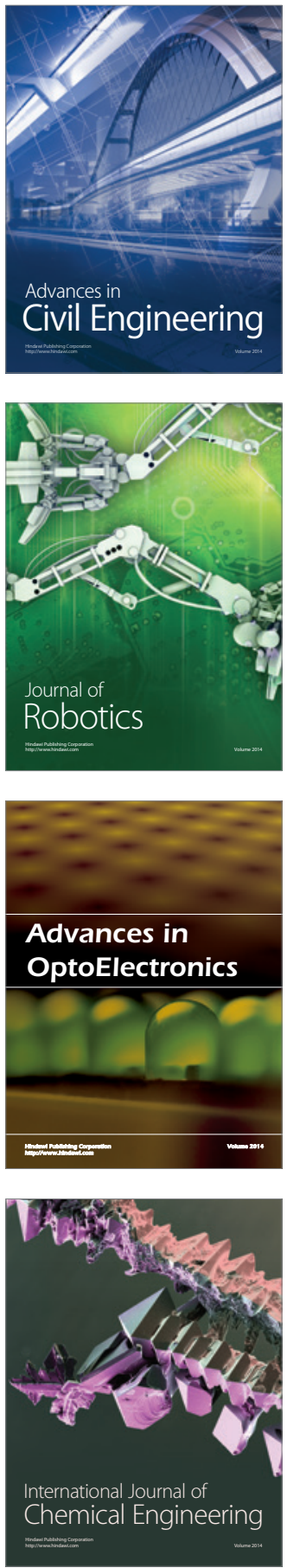

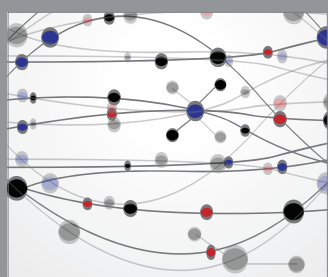

The Scientific World Journal

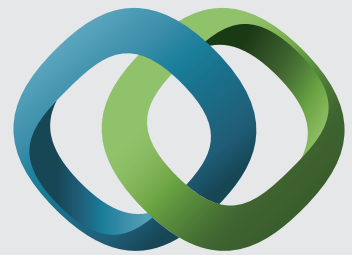

\section{Hindawi}

Submit your manuscripts at

http://www.hindawi.com
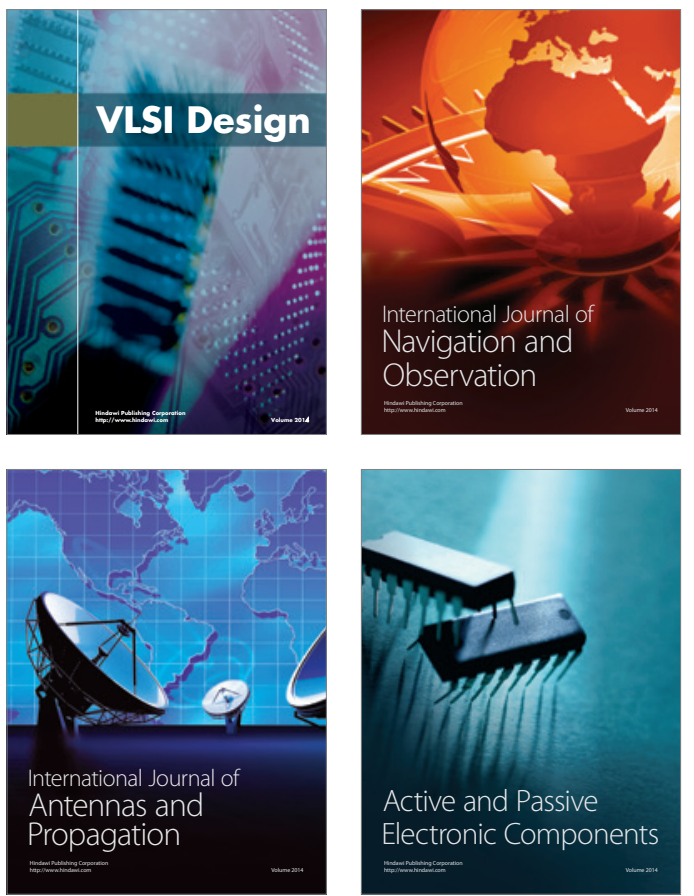
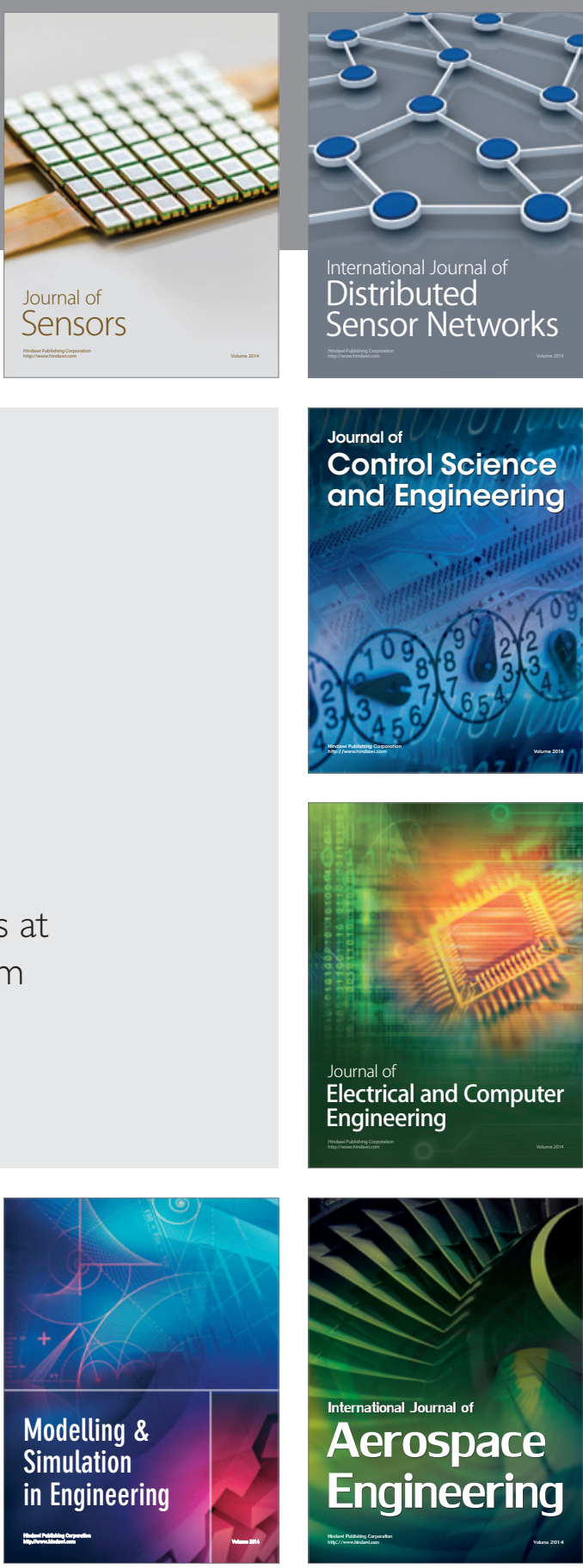

International Journal of

Distributed

Sensor Networks

Journal of

Control Science

and Engineering
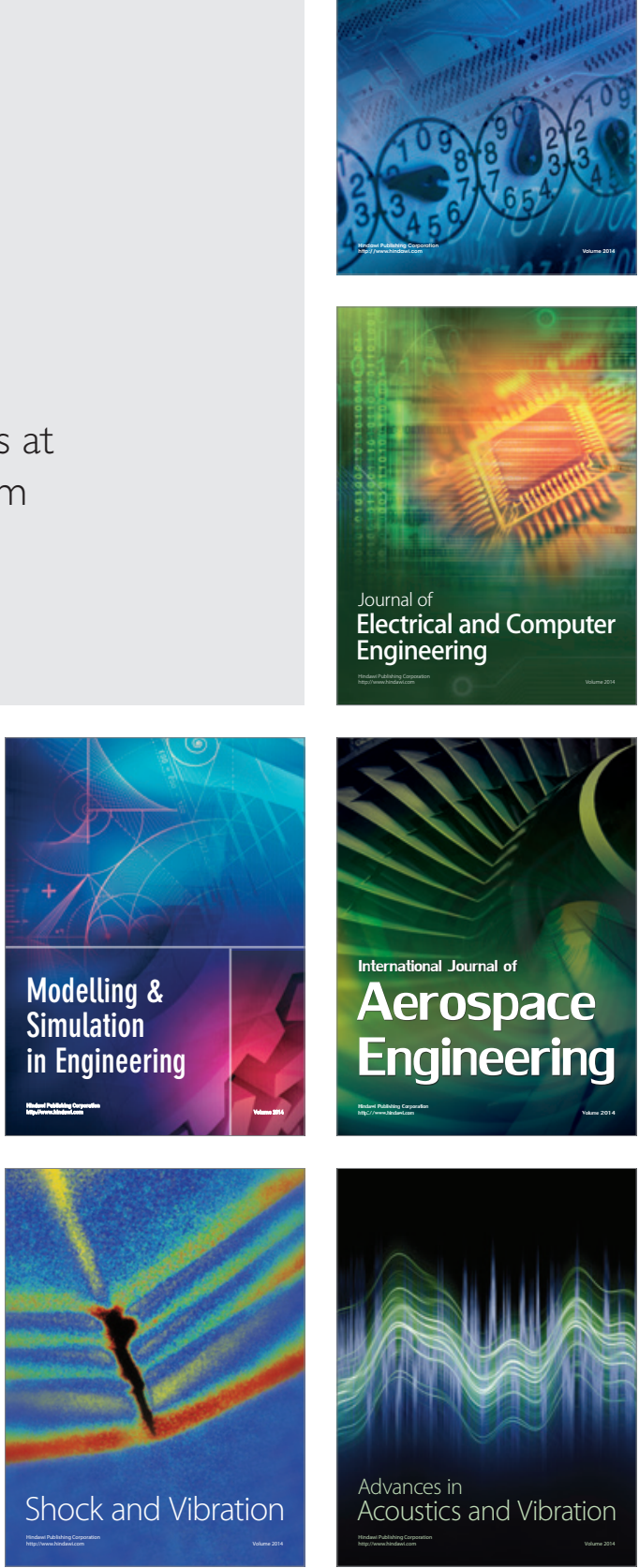